\title{
FIBROSARCOMA OF LONG BONES
}

\author{
A STUDY OF THE SIGNIFICANCE OF AREAS OF MALIGNANT FIBROUS HISTIOCYTOMA
}

\author{
W. K. TACONIS, TH. G. VAN RIJSSEL
}

\author{
From the Onze Lieve Vrouwe Gasthuis, Amsterdam, and University Hospital, Leiden
}

\begin{abstract}
A study was made of the clinical course of 102 cases of fibrosarcoma of long bones. Of these, 55 were predominantly fibroblastic or pure fibrosarcomata while 47 contained extensive areas resembling so-called malignant fibrous histiocytoma (MFH). Treatment was similar in the two groups, and the five-year survival was the same, $34 \%$, in both groups. Lung metastases developed in $63 \%$ of the fibroblastic sarcomata and $59 \%$ of the MFH-like tumours. Our study indicates that there is no significant difference in behaviour in fibrosarcoma with or without marked MFH features. The histological grading of both groups of fibrosarcomata together was of prognostic value; five-year survival was $64 \%$ in 14 Grade I tumours, $41 \%$ in 32 Grade II tumours and $23 \%$ in 56 Grade III tumours.
\end{abstract}

Fibrosarcoma of bone is a primary malignant tumour with a fibrous intercellular substance in which no osteoid or cartilage is formed. MacDonald and Budd in 1943 and Phemister in 1948 were among the first to consider fibrosarcoma to be a distinctive neoplasm of the skeleton. The reported incidence varies from $4 \%$ to $8 \%$ of all primary malignant bone tumours (Netherlands Committee on Bone Tumours 1966; Aegerter and Kirkpatrick 1968; Huvos and Higinbotham 1975; Larsson, Lorentzon and Boquist 1976; Campanacci and Olmi 1977; Pritchard et al. 1977; Mirra 1980; Schajowicz 1981; Taconis 1982; Wilner 1982).

Fibrosarcoma of bone manifests itself fairly evenly from the second to the seventh decade and, like osteosarcoma, usually involves the metaphysial part of the long bones, especially near the knee. Reported fiveyear survival rates vary from $26 \%$ to $34 \%$ (Gilmer and MacEwen 1958; Netherlands Committee on Bone Tumours 1966; Aegerter and Kirkpatrick 1968; Cunningham and Arlen 1968; Dahlin and Ivins 1969; EyreBrook and Price 1969; Huvos and Higinbotham 1975; Jeffree and Price 1976; Pritchard et al. 1977; Schajowicz 1981; Taconis 1982; Wilner 1982).

Apart from its appearance de novo, fibrosarcoma may develop as a secondary change in such abnormal tissues as irradiated bone, areas of Paget's disease and of chronic osteomyelitis, and after progression or dedifferentiation, mainly from chondrosarcoma (Dahlin 1978; Schajowicz 1981; Wilner 1982).

W. K. Taconis, MD, Radiologist

Onze Lieve Vrouwe Gasthuis, le Oosterparkstraat 179, 1091 HA Amsterdam, The Netherlands.

Th. G. van Rijssel, MD, Pathologist

Leiden University Hospital, Leiden, The Netherlands.

Requests for reprints should be sent to $\mathrm{Dr} W$. K. Taconis.

(C) 1985 British Editorial Society of Bone and Joint Surgery $0301-620 \times / 85 / 1064 \$ 2.00$
It was not until 1972 that malignant fibrous histiocytoma (MFH) was first reported as a primary malignant tumour of bone (Feldman and Norman 1972). It had previously been described in the soft tissues, and especially in the thigh and the trunk. The tumour shows both histiocytic and fibroblastic features. After 1972, other reports described MFH in bone (Mirra et al. 1974; Spanier, Enneking and Enriquez 1975; Huvos 1976; Inada et al. 1976; Michael and Dorfman 1976; Yumoto et al. 1976; Dahlin, Unni and Matsuno 1977; Feldman and Lattes 1977; Meister and Konrad 1977; Mirra, Gold and Marafiote 1977; Spanier 1977; Kahn et al. 1978; Dunham and Wilborn 1979; McCarthy, Matsuno and Dorfman 1979; Freyschmidt et al. 1981). Most of these reports were compiled by screening already available histological material from primary malignant bone tumours which had been classified as fibrosarcoma, osteosarcoma, and malignant giant-cell sarcoma.

Like fibrosarcoma, malignant fibrous histiocytoma was found predominantly in adults, evenly distributed in onset from the second to the seventh decade. It also most frequently involved the metaphysial part of the long bones. Several authors describe MFH of bone occurring in association with pre-existing bone abnormality and especially bone infarcts (Mirra et al. 1974; Michael and Dorfman 1976; Mirra et al. 1977; Galli, Weintraub and Proppe 1978; Sanerkin and Woods 1979). Early reports suggested a very poor prognosis, but more recent communications quote a five-year survival of $25 \%$ to $33 \%$ (Dahlin et al. 1977; McCarthy et al. 1979).

In the records of fibrosarcoma of long bones of the Netherlands Committee on Bone Tumours, a number of cases were found which had originally been classified as pleomorphic fibrosarcoma. In slides of these tumours, areas resembling malignant fibrous histiocytoma (MFH) were found. To establish the importance of MFH areas 
in the course of the disease, we divided these cases into two groups; those which were predominantly fibroblastic or fibrosarcomata, and those with extensive MFH-like areas.

\section{MATERIAL AND METHODS}

From 1953 to 1976, 102 cases of fibrosarcoma of long bones were registered in the files of the Netherlands Committee on Bone Tumours. Fibrosarcoma of soft tissue with secondary erosion of bone was excluded. There were pre-existing bony abnormalities in 15 cases: irradiated bone in three, Paget's disease in two, chronic osteomyelitis in one, and in seven a progression from chondrosarcoma; two cases occurred long after local surgery for a benign tumour (13 years after a chondroblastoma in one, and 20 years after a giant-cell tumour in the other).

Histological slides of tumour tissue were available for all cases. This material was reviewed and the series was divided into those cases with pure or predominantly fibroblastic tumours and those with extensive areas resembling MFH. The histology of fibrosarcoma includes fibroblast-like cells with fine collagen fibres arranged in intertwined bundles, often in a so-called herring-bone pattern. There is considerable variation in the amount of fibres, atypical nuclei and number of mitotic figures, but generally there is reasonable correlation between the histological differentiation and the clinical behaviour of the tumour (Netherlands Committee on Bone Tumours 1966). A number of tumours also contain areas resembling malignant fibrous histiocytoma, characterised by elongated spindle cells, arranged in a pinwheel or storiform fashion, and cells with histiocytic features such as pleomorphic folded or grooved nuclei with abundant, often foamy cytoplasm. Polynuclear giant cells and very large nuclei are often present.

Using these criteria 55 fibrosarcomata $(54 \%)$ had predominantly fibroblastic features and $47(46 \%)$ had extensive MFH-like areas.

The tumours were graded histologically according to the system of the Netherlands Committee on Bone Tumours (1966) as follows: Grade I-weH-differentiated tumour tissue with very few mitoses in the most cellular parts of the tumour (less than 2 in 20 high-power fields, each of $250 \mu \mathrm{m}$ diameter); Grade II-moderately differentiated tumour tissue (less than 10 mitoses per 20 highpower fields in the most cellular areas); and Grade IIIhigh mitotic rate (10 or more mitoses in 20 high-power fields).

The radiological material available included plain films for all cases and tomograms for the majority. The destruction of bone was described using Lodwick's classification into basic patterns termed geographic, moth-eaten and permeative (Lodwick 1971; Lodwick et al. 1980). The results of angiography, bone scintigraphy and computerised tomography were available for only some of the cases.

Information on the course of the disease was
Table I. The anatomical distribution of mainly pure fibrosarcoma and of fibrosarcoma with MFH features

\begin{tabular}{|llcc|}
\hline Site & & $\begin{array}{l}\text { Fibrosarcoma } \\
n=55\end{array}$ & $\begin{array}{l}\text { MFH } \\
n=47\end{array}$ \\
\hline Femur & $\begin{array}{l}\text { proximal } \\
\text { diaphysial } \\
\text { distal }\end{array}$ & 7 & 9 \\
Tibia & $\begin{array}{l}\text { proximal } \\
\text { diaphysial } \\
\text { distal }\end{array}$ & 7 & 3 \\
& Humerus & 0 & 21 \\
Fibula & proximal & 7 & 5 \\
& diaphysial & 2 & 0 \\
Radius & proximal & 2 & 1 \\
& diaphysial & 1 & 0 \\
& distal & 1 & 0 \\
\hline
\end{tabular}

available for all patients and five-year survival figures were calculated according to Peto et al. (1977).

\section{RESULTS}

Clinical presentation. The age and sex distribution of patients in the groups with pure fibrosarcoma and with sarcoma including MFH areas are shown in Figure 1. There were somewhat more young patients with mainly pure fibrosarcoma; the mean age in that group was 47 years against 55 years in the MFH group.

The anatomical distribution of tumours is shown in Table I. For both tumour types the most frequent site was the femur, which was involved in $62 \%$ of the pure fibrosarcomata and in $70 \%$ of the tumours with MFH areas. The tibia, usually proximally, and the humerus, mostly proximally, were less frequently affected; tumours were rare in the fibula and in the radius. Both tumour types were seen mostly in the meta-diaphysis $(67 \%)$, less frequently in the meta-epiphysial region $(26 \%)$ and

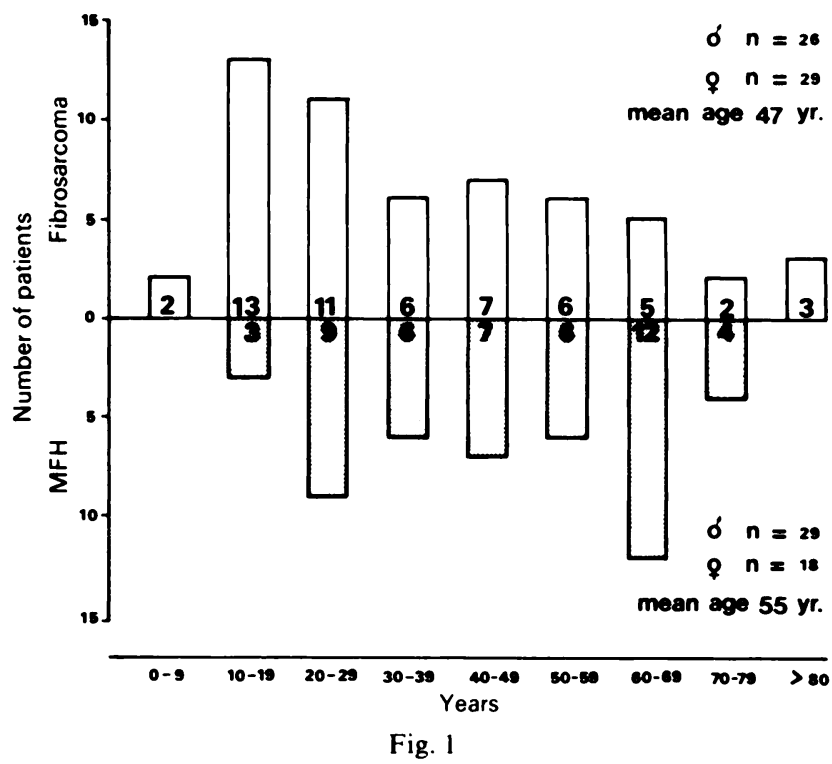

The age and sex distribution of 55 patients with mainly pure fibrosarcoma (open columns) and 47 patients with fibrosarcoma having MFH features (shaded). 
seldom in the diaphysis $(7 \%)$. In the femur all midshaft fibrosarcomata showed MFH features, but in the humerus, the tibia and the fibula, diaphysial lesions were all pure fibrosarcomata.

No significant difference was found between the clinical presentation of patients in the two groups. Pain was the most common presenting symptom $(87 \%)$, swelling being less frequent $(31 \%)$. In each of the tumour types 13 patients presented with a pathological fracture; half of these patients had no symptoms before the fracture. The duration of symptoms before diagnosis was the same in both groups, being less than six months in $82 \%$ of all cases and less than three months in $62 \%$.

Radiological features. Intra-osseous fibrosarcomata with areas of malignant fibrous histiocytoma were indistinguishable on radiography from those without; both showed radiolucency, often with a moth-eaten appearance or with a combination of moth-eaten and permeative destruction and a broad zone of transition (Figs 2 to 5).

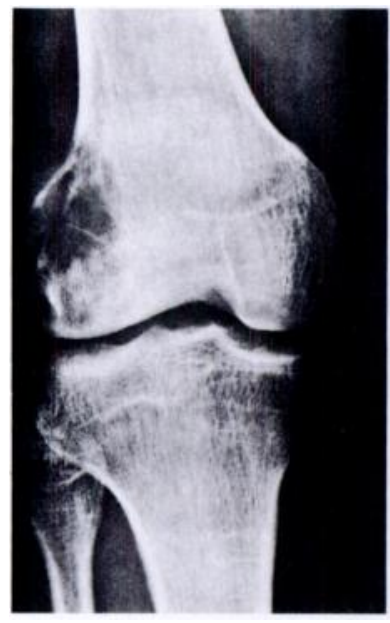

Fig. 2

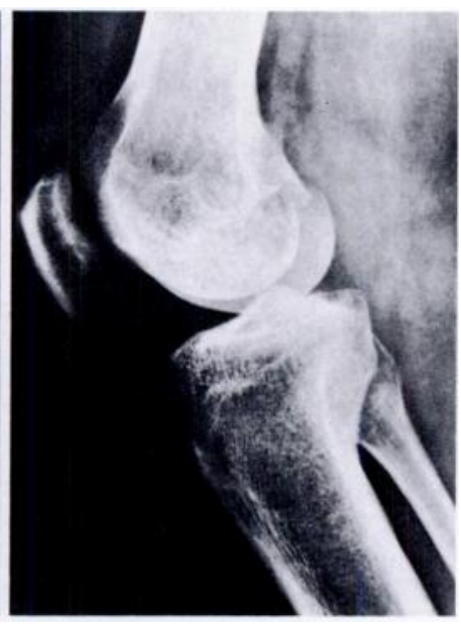

Fig. 3
Radiological appearance of pure fibrosarcoma of bone in the dista femur showing a combined moth-eaten and permeative pattern of bone destruction.

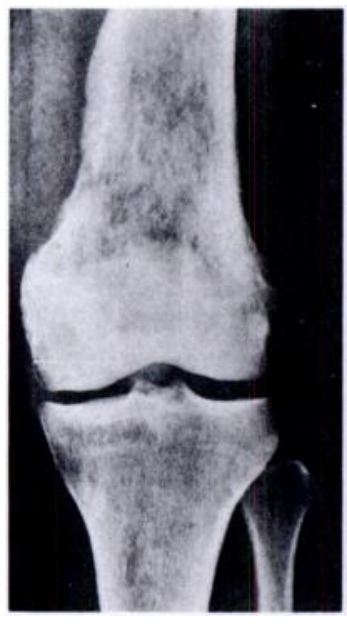

Fig. 4

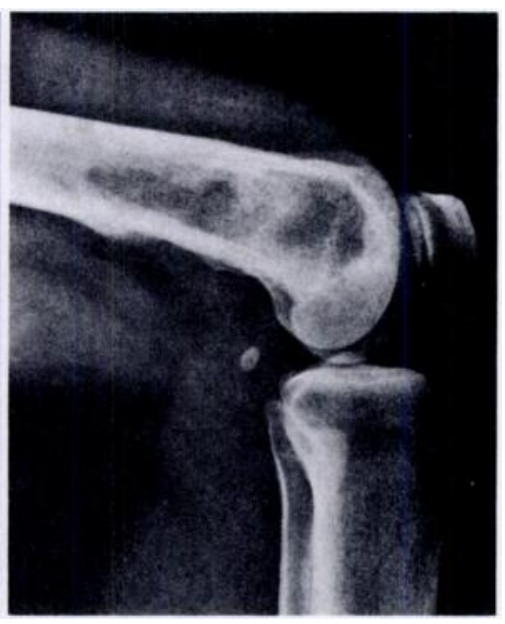

Fig. 5
Radiological appearance of fibrosarcoma with MFH features in the distal femur with eccentric location, showing a moth-eaten pattern of bone destruction.
Table II. The radiological pattern of bone destruction of mainly pure fibrosarcoma and of fibrosarcoma with areas of MFH

\begin{tabular}{|c|c|c|c|c|}
\hline $\begin{array}{l}\text { Destructive } \\
\text { pattern }\end{array}$ & $\begin{array}{l}\text { Fibrosarc } \\
n=53 \\
\text { Number }\end{array}$ & $\begin{array}{c}\text { oma } \\
\%\end{array}$ & $\begin{array}{l}\text { MFH } \\
n=47 \\
\text { Number }\end{array}$ & $\%$ \\
\hline Geographic & 7 & 13 & 8 & 17 \\
\hline $\begin{array}{l}\text { Moth eaten or } \\
\text { Moth eaten/permeative }\end{array}$ & 39 & 74 & 35 & 75 \\
\hline Permeative & 7 & 13 & 4 & 9 \\
\hline
\end{tabular}

The pattern of bone destruction was reviewed in 100 cases; in two cases films taken before treatment were not available. A pure geographic pattern of bone destruction was found in 15 cases: seven had pure fibrosarcoma, and eight had tumours with MFH areas. There was a purely permeative pattern in 11 cases: seven pure fibrosarcoma, four MFH. The other 74 cases had either a moth-eaten appearance, or a combined central moth-eaten and peripheral permeative destructive pattern, which was found equally in each tumour group (Table II). The length of the bone destruction caused by the lesion had the same distribution in both groups: it was between 7 and $10 \mathrm{~cm}$ in $51 \%$ of the films, less than $7 \mathrm{~cm}$ in $29 \%$ and larger than $11 \mathrm{~cm}$ in $20 \%$. Periosteal bone formation, though not extensive, was present in most lesions. The most frequent appearance, in $73 \%$, was a lamellar reaction, mostly interrupted and ill-defined, while spicules were seen in only $10 \%$ and Codman's triangles in $26 \%$; there was no periosteal reaction in 15 cases. There were no significant differences in periosteal bone formation between the two groups of tumours.

Soft-tissue extension of the tumours was not investigated fully because special films and CT scans were not available at the time when most of the cases had been registered. In 17 cases, evenly distributed between the two histological groups, some indications of tumour extension outside bone were seen on plain films.

Histological review placed 14 cases in Grade I, 32 in Grade II and 56 cases in Grade III.

Treatment and survival. The survival curves for patients in both the pure fibrosarcoma group and the sarcoma with MFH group are shown in Figure 6. The five-year survival in both groups was $34 \%$; at 10 years it was $32 \%$. Patients registered from 1953 to 1976 were treated in many different hospitals in The Netherlands by radical or ablative surgery, local excision or radiotherapy. The percentage of patients in either group treated by radical surgery was not significantly different, being $62 \%$ without and $63 \%$ with MFH. It is therefore justifiable to compare directly the course of the disease in the histologically different types of sarcoma.

Tumour recurrence, usually after inadequate surgery, occurred as frequently in both types of tumour: in 9 of $55(16 \%)$ in the pure fibrosarcomata and in 8 of 47 $(17 \%)$ in patients whose tumours had features of MFH. 


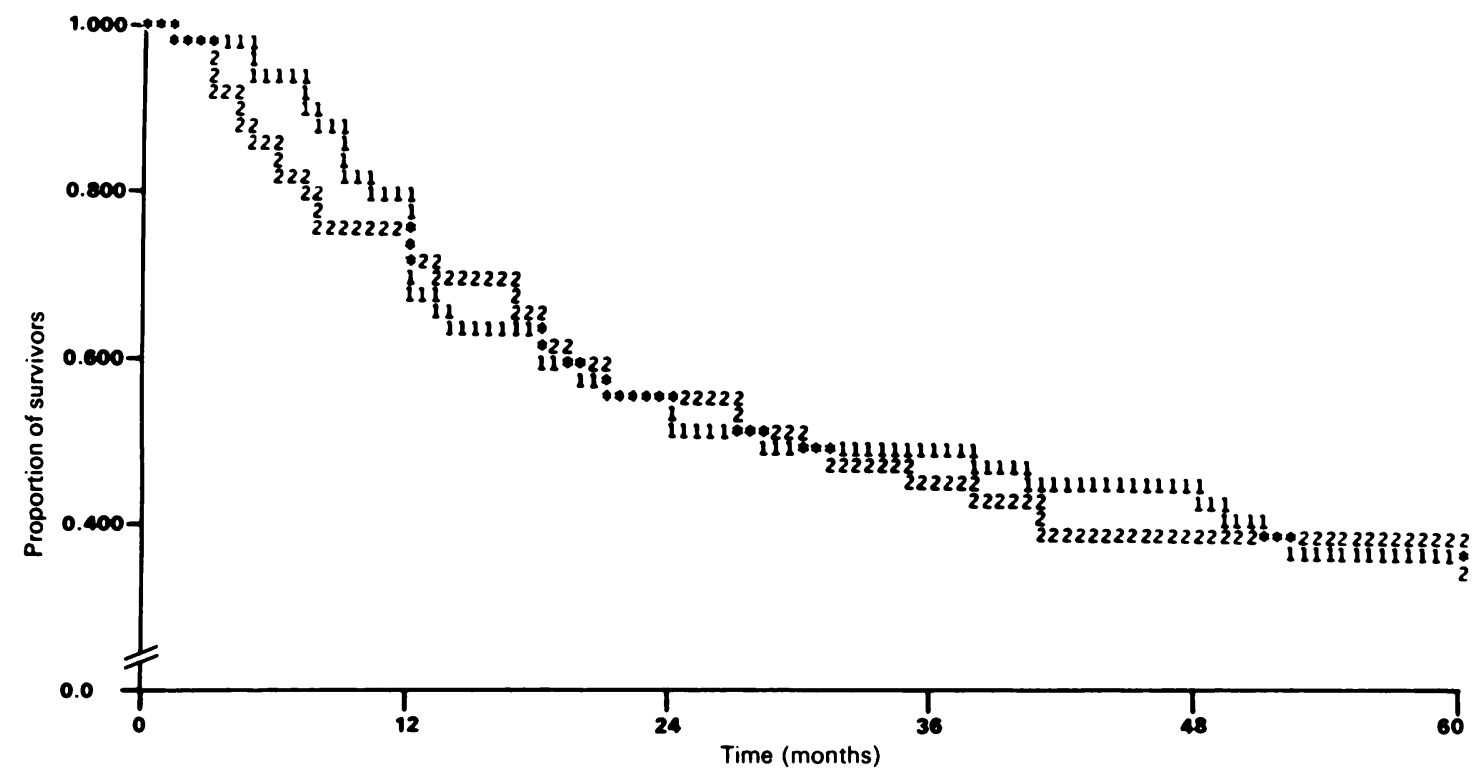

Fig. 6

Five-year survival curves for 55 patients with mainly pure fibrosarcoma (1) and 47 patients with MFH features (2); the stars indicate where the curves for the two groups are the same.

Soft-tissue recurrence developed in the stump of one patient with an MFH-type tumour of the proximal femur and in the stumps of two patients with the fibroblastic type of tumour.

In $68 \%$ of those who developed lung metastases these appeared in the first year. They were found nearly equally in patients without and with MFH features: in $63 \%$ and $59 \%$ respectively within 5 years (Fig. 7). In only two cases, both tumours with MFH areas, did lung metastases develop late: in one case after 9 years and in the other after 10 years. The mean interval between the detection of lung metastases and death was 9 months; but only a few patients had received aggressive treatment by surgery or chemotherapy for their lung metastases during the period being reported. Survival was no longer after the late development of lung metastases than it was when they presented soon after primary treatment.

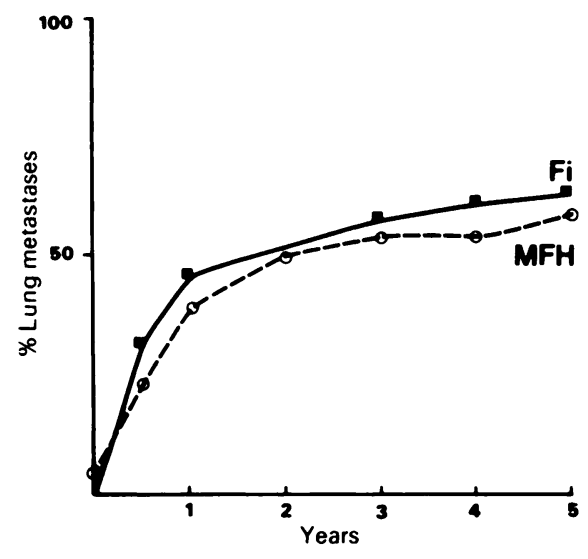

Fig. 7

Cumulative percentage incidence of lung metastases over five years in 55 patients with mainly pure fibrosarcoma (Fi) and 47 patients with fibrosarcoma with MFH features.
Information on metastases to bone and elsewhere was less complete. Bone metastases developed, usually in the terminal stage, in 16 cases, equally divided between the histological types of sarcoma. Lymph node metastases were found in four patients : one with a tumour containing MFH areas and three with pure fibrosarcoma.

There was a good correlation between histological grading and survival (Fig. 8). The five-year survival in Grade I ( 14 cases) was $64 \%$, in Grade II ( 32 cases) it was $41 \%$, and in Grade III (56 cases) it was $23 \%$.

\section{DISCUSSION}

Fibrosarcoma of the skeleton comprises $8 \%$ of the primary malignant bone tumours in the material of the Netherlands Committee on Bone Tumours. The prognosis of fibrosarcoma of bone is generally considered to be more favourable than that of osteosarcoma (Gilmer and MacEwen 1958; Netherlands Committee on Bone Tumours 1966; Aegerter and Kirkpatrick 1968; Cunningham and Arlen 1968; Dahlin and Ivins 1969; EyreBrook and Price 1969; Huvos and Higinbotham 1975; Jeffree and Price 1976; Pritchard et al. 1977; Taconis 1982; Schajowicz 1981; Wilner 1982).

Earlier reports indicated that MFH of bone had a poor prognosis but more recent papers have suggested a more favourable course for the disease and state that it is less aggressive than osteosarcoma or fibrosarcoma (Dahlin et al. 1977; McCarthy et al. 1979). We are not aware of any reports on long-term survival of patients with MFH of bone (Dunham and Wilborn 1979; Freyschmidt et al. 1981).

Among the 102 patients reported, we were able to separate cases with pure fibrosarcoma from cases in which extensive areas resembling MFH were found, and 


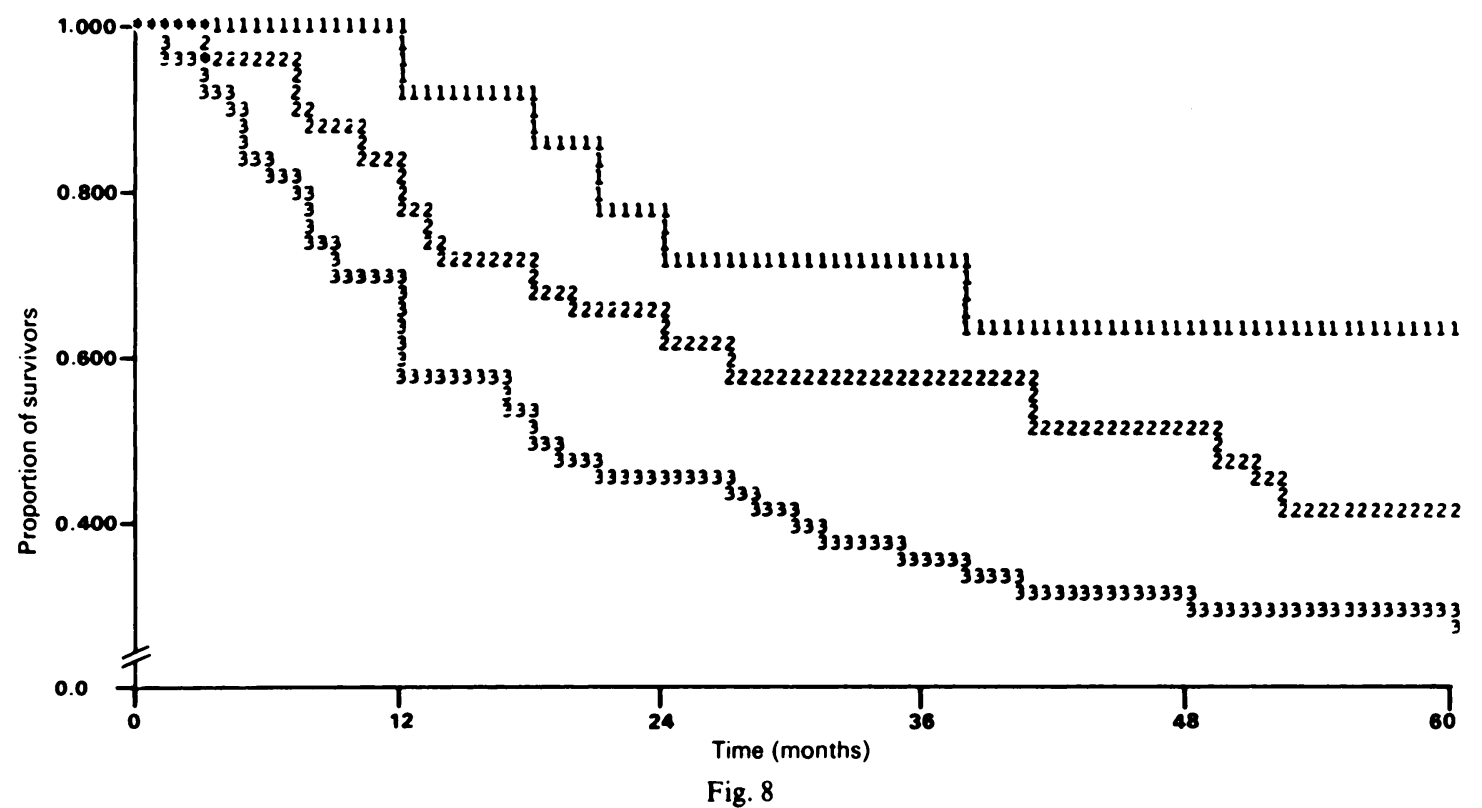

Five-year survival curves for 102 patients according to histological grading. Key: 1, Grade I, 14 cases; 2, Grade II, 32 cases; 3 , Grade III, 56 cases; the stars indicate where the curves for the three grades are the same.

to compare the groups over a relatively long period of time. The clinical features and presentation of patients differed only in that patients with pure fibrosarcoma were generally younger, with a mean age of 47 years, as against 55 years for MFH tumours. A relative predilection of MFH for male patients, with a ratio of 1.6 to 1 , has also been reported by others (Dunham and Wilborn 1979; Freyschmidt et al. 1981) and seems more definite than in other bone sarcomata. The anatomical locations, mainly in the femur, tibia and humerus, and the clinical presentation with pain and swelling as the chief symptoms, were not different in the two groups.

The five-year survival curves of patients (Fig. 6) with the two histologically different tumours were very similar. There was no significant difference in therapy between the two groups; as mentioned above, radical or ablative surgery was carried out in a similar number in each group. At present it is generally accepted that radical surgery is the best treatment for both types of fibrosarcoma of the long bones; not enough results are yet available to judge the efficacy of limb-preservation by en bloc resection with reconstruction, alone or in combination with chemotherapy.

The development of lung metastases in both types of fibrosarcoma of bone, as in other sarcomata, is the factor which determines survival, rather than recurrence of the tumour itself. Lung metastases were found in $63 \%$ of the cases of mainly pure fibrosarcoma and in $59 \%$ of sarcomata with MFH features, regardless of the method of treatment; in $68 \%$ of these cases metastases were detected within one year of treatment.

Feldman and Norman (1972) and Spanier et al. (1975) have suggested that MFH has a propensity to metastasise to the lymph nodes, a site which is rather rare in either fibrosarcoma or osteosarcoma (Huvos
1976). In a review of the literature Dunham and Wilborn (1979) reported that of 111 patients with MFH of bone only six developed metastatic deposits in adjacent lymph nodes. We found involvement of the lymph nodes in three cases of mainly pure fibrosarcoma and in only one case of MFH-like fibrosarcoma.

The radiological appearance in both groups was predominantly that of a malignant tumour, though in a few cases the radiographs suggested a benign lesion. Sequestration or calcification within the osteolytic area of the lesion was not found. Some radiological signs are of help in estimating the prognosis of either form of bone sarcoma, as we have reported elsewhere (Taconis 1982).

Several authors report a much higher survival rate in a so-called periosteal type of fibrosarcoma than in the usual medullary fibrosarcoma (Aegerter and Kirkpatrick 1968; Huvos and Higinbotham 1975; Campanacci and Olmi 1977; Schajowicz 1981; Wilner 1982). No firm criteria have been given which establish a periosteal origin. We have not found such a case in our series, but we have seen several cases of primary soft-tissue fibrosarcoma causing secondary erosion of bone. The prognosis of soft-tissue fibrosarcoma is known to be more favourable than that of intra-osseous fibrosarcoma (van der Werf-Messing and van Unnik 1965; Pritchard et al. 1974). Excluding such soft-tissue tumours, we distinguished between central and eccentric tumours in our radiographs and found significant differences in survival between them; five-year survival was $31 \%$ for central tumours and $75 \%$ for eccentric tumours $(P<0.0028)$. This distinction seems more meaningful than that between medullary and periosteal fibrosarcoma.

The classification of bone tumours is largely based on histological criteria, and several bone tumours may contain foci resembling MFH. These include fibro- 
sarcoma, osteosarcoma, malignant giant-cell tumour, dedifferentiated chondrosarcoma, radiation sarcoma and even metastatic carcinoma (Dahlin et al. 1977). The histological criteria are not exclusive and we have shown that the clinical findings and course are not clearly different. It is therefore questionable whether pure fibrosarcoma and fibrosarcomatous tumours with MFH features should be considered to be different entities. In our opinion it seems best to regard so-called MFH of bone as a histiocytic variety of skeletal fibrosarcoma.

The authors wish to thank Mr B. Walman for the preparation of the illustrations.

\section{REFERENCES}

Aegerter EE, Kirkpatrick JA Jr. Fibrosarcoma of bone. Orthopedic diseases: physiology, pathology, radiology. 3rd ed. Philadelphia, London, Toronto: WB Saunders, 1968:670-8.

Campanacci M, Olmi R. Fibrosarcoma of bone: a study of 114 cases. Ital J Orthop Traumatol 1977:3:199-206.

Cunningham MP, Arlen M. Medullary fibrosarcoma of bone. Cancer $1968: 21: 31-7$

Dahlin DC. Bone tumours: general aspects and data on 6221 cases. 3rd ed. Springfield: CC Thomas, 1978.

Dahlin DC, Ivins JC. Fibrosarcoma of bone: a study of 114 cases. Cancer 1969:23:35-41.

Dahlin DC, Unni KK, Matsuno T. Malignant (fibrous) histiocytoma of bone-fact or fancy? Cancer 1977:39:1508-16.

Dunham WK, Wilborn WH. Malignant fibrous histiocytoma of bone: report of two cases and review of the literature. J Bone Joint Surg [Am] 1979:61-A:939-42.

Eyre-Brook AL, Price CHG. Fibrosarcoma of bone: review of fifty consecutive cases from the Bristol Bone Tumour Registry. J Bone Joint Surg [Br] 1969:51-B: 20-37.

Feldman F, Lattes R. Primary malignant fibrous histiocytoma (fibrous xanthoma) of bone. Skeletal Radiol 1977:1:145-60.

Feldman F, Norman D. Intra- and extraosseous malignant histiocytoma (malignant fibrous xanthoma). Radiology 1972;104:497-508.

Freyschmidt J, Ostertag H, Majewski A, Korvalian Z. Das maligne fibröse Histiozytom des Knochens (MFH): eine neue Tumorentität? Fortschr Röntgenstr 1981:135:1-12.

Galli SJ, Weintraub HP, Proppe KH. Malignant fibrous histiocytoma and pleomorphic sarcoma in association with medullary bone infarcts. Cancer 1978:41:607-19.

Gilmer WS Jr, MacEwen GD. Central (medullary) fibrosarcoma of bone. J Bone Joint Surg [Am] 1958;40-A:121-41.

Huvos AG. Primary malignant fibrous histiocytoma of bone: clinicopathologic study of 18 patients. NY State J Med 1976;76 (4):5529.

Huvos AG, Higinbotham NL. Primary fibrosarcoma of bone: a clinicopathologic study of 130 patients. Cancer 1975; 35:837-47.

Inada O, Yumoto T, Furuse K, Tanaka T. Ultrastructural features of malignant fibrous histiocytoma of bone. Acta Pathol Jpn 1976; 26 (4): 491-501.

Jeffree GM, Price CHG. Metastatic spread of fibrosarcoma of bone : a report on forty-nine cases and a comparison with osteosarcoma. $J$ Bone Joint Surg [Br] 1976:58-B:418-25.

Kahn LB, Webber B, Mills E, Anstey L, Heselson NG. Malignant fibrous histiocytoma (malignant fibrous xanthoma: xanthosarcoma) of bone. Cancer 1978:42:640-51.

Larsson S-E, Lorentzon R, Boquist L. Fibrosarcoma of bone: a demographic, clinical and histopathological study of all cases in the Swedish Cancer Registry from 1958 to 1968. J Bone Joint Surg [Br] 1976:58-B:412-7.

Lodwick GS. The bones and joints. In: Hodes PJ, ed. Atlas of tumour radiology. Chicago: Year Book Medical Publishers, 1971.
Lodwick GS, Wilson AJ, Farrell C, Virtama P, Smeltzer FM, Dittrich F. Estimating rate of growth in bone lesions: observer performance and error. Radiology 1980:134:585-90.

MacDonald I, Budd JW. Osteogenic sarcoma : modified nomenclature and review of 118 five year cures. Surg G.necol Obstet 1943:77:41321.

McCarthy EF, Matsuno T, Dorfman HD. Malignant fibrous histiocytoma of bone: a study of 35 cases. Hum Pathol 1979:10 (1):57-70.

Meister P, Konrad E. Malignes fibröses Histiozytom des Knochens (8 Jahre nach Strahlenexposition). Arch Orthop Unfallchir 1977;90:95-101.

Michael RH, Dorfman HD. Malignant fibrous histiocytoma associated with bone infarcts: report of a case. Clin Orthop 1976:118:180-3.

Mirra JM. Bone tumors: diagnosis and treatment. Philadelphia: JB Lippincott, 1980.

Mirra JM, Bullough PG, Marcove RC, Jacobs B, Huvos AG. Malignant fibrous histiocytoma and osteosarcoma in association with bone infarcts: report of four cases, two in caisson workers. J Bone Joint Surg $[\mathrm{Am}] 1974: 56-\mathrm{A}: 932-40$.

Mirra JM, Gold RH, Marafiote R. Malignant (fibrous) histiocytoma arising in association with a bone infarct in sickle-cell disease: coincidence or cause-and-effect? Cancer 1977:39: 186-94.

Netherlands Committee on Bone Tumours. Radiological atlas of bone tumours, Vol. 1. The Hague, Paris: Mouton, 1966.

Peto R, Pike MC, Armitage P, et al. Design and analysis of randomized clinical trials, requiring prolonged observation of each patient: II, analysis and examples. Br J Cancer 1977;35:1-39.

Phemister DB. Cancer of the bone and joint. JAMA 1948: 136:545-54.

Pritchard DJ, Soule EH, Taylor WF, Ivins JC. Fibrosarcoma: a clinicopathologic and statistical study of 199 tumors of the soft tissues of the extremities and trunk. Cancer 1974:33:888-97.

Pritchard DJ, Sim FH, Ivins JC, Soule EH, Dahlin DC. Fibrosarcoma of bone and soft tissues of the trunk and extremities. Orthop Clin North Am 1977;8 (4):869-81.

Sanerkin NG, Woods CG. Fibrosarcoma and malignant fibrous histiocytomata arising in relation to enchondromata. $J$ Bone Joint Surg [Br] 1979;61-B: $366-72$.

Schajowicz F. Tumors and tumorlike lesions of bone and joints. New York, Heidelberg, Berlin: Springer-Verlag, 1981.

Spanier SS. Malignant fibrous histiocytoma of bone. Orthop Clin North Am 1977:8 (4):947-61.

Spanier SS, Enneking WF, Enriquez P. Primary malignant fibrous histiocytoma of bone. Cancer 1975:36:2084-98.

Taconis WK. Fibrosarcooa tan het skelet: een klinisch-radiologisch onderzoek. Thesis, Leiden University, 1982.

van der Werf-Messing B, van Unnik JAM. Fibrosarcoma of the soft tissues: a clinicopathologic study. Cancer 1965;18:1113-23.

Wilner D. Radiology of bone tumors and allied disorders. Philadelphia, London: WB Saunders, 1982.

Yumoto T, Mori Y, Inada O, Tanaka T. Malignant fibrous histiocytoma of bone. Acta Pathol Jpn 1976:26 (3): 295-309. 